Check for updates

Cite this: Phys. Chem. Chem. Phys., 2018, 20, 21573

Received 7th April 2018,

Accepted 14th July 2018

DOI: $10.1039 / \mathrm{c} 8 \mathrm{cp} 02207 \mathrm{k}$

rsc.li/pccp

\section{Uptake and accommodation of water clusters by adamantane clusters in helium droplets: interplay between magic number clusters}

\author{
Lorenz Kranabetter, ${ }^{a}$ Paul Martini, ${ }^{a}$ Norbert Gitzl, ${ }^{a}$ Martin Kuhn, ${ }^{a}$ Fatima Saleem, ${ }^{b}$ \\ Bilal Rasul, ${ }^{b}$ Masoomeh Mahmoodi Darian, ${ }^{c}$ Elias Jabbour Al Maalouf, ${ }^{a}$ \\ Ivan Sukuba, (D) ${ }^{d}$ Alexander Kaiser, (D) ${ }^{a}$ Marcelo Goulart, (D) ${ }^{a}$ Diethard K. Böhme* \\ and Paul Scheier (D)*a
}

\begin{abstract}
We report an experimental study of water clusters as guests in interactions with clusters of adamantane (Ad) as hosts that occur in doped helium droplets at extremely low temperatures. Separate experiments with pure water as dopant showed ready formation of a distribution of water clusters $\left(\mathrm{H}_{2} \mathrm{O}\right)_{m} \mathrm{H}^{+}$that peaks at $m=11$ and extends beyond $m=100$ with local maxima at $m=4,11,21,28$ and 30 with $\left(\mathrm{H}_{2} \mathrm{O}\right)_{21} \mathrm{H}^{+}$being the most anomalous and showing the greatest stability with respect to clusters immediately adjacent in water content. When adamantane is also added as a dopant, extensive hydration is seen in the formation of water/adamantane clusters, $\left(\mathrm{H}_{2} \mathrm{O}\right)_{m} \mathrm{Ad}_{n}{ }^{+}$; magic number clusters $\left(\mathrm{H}_{2} \mathrm{O}\right)_{21} \mathrm{Ad}_{n}{ }^{+}$ are seen for all the adamantane clusters. Other magic numbers for water clusters attached to adamantane, $\left(\mathrm{H}_{2} \mathrm{O}\right)_{m} \mathrm{Ad}_{n}{ }^{+}$, are as for pristine protonated water, with $m=28$ and $m=30$. The icosahedral shell closure of pure adamantane at $n=13$ and 19 appears to be preserved with $\left(\mathrm{H}_{2} \mathrm{O}\right)_{21}$ replacing one adamantane. $\left(\mathrm{H}_{2} \mathrm{O}\right)_{21} \mathrm{Ad}_{12}{ }^{+}$and $\left(\mathrm{H}_{2} \mathrm{O}\right)_{21} \mathrm{Ad}_{18}{ }^{+}$stand out in intensity and demonstrate the interplay of magic number water clusters with magic number adamantane clusters, observed perhaps for the first time in gas-phase cluster chemistry. There was no clear evidence for the formation of clathrate hydrates in which adamantane is trapped within structured water
\end{abstract}

\section{Introduction}

Water is omnipresent in biological and chemical environments where it is often accommodated by molecular aggregates as clusters of water. ${ }^{1-4}$ The accommodation of the uniquely stable $\left(\mathrm{H}_{2} \mathrm{O}\right)_{21}$ cluster is of particular interest, both in solution and in the gas phase, and so has been the focus of many experimental investigations. $^{5-8}$ For example, Cao et al. recently reported a study of template trapping and crystal structure of the magic number $\left(\mathrm{H}_{2} \mathrm{O}\right)_{21}$ cluster in the tetrahedral hole of a nanoscale global ion packed in a face-centered cubic pattern. ${ }^{9}$ Other experimental studies have explored the confinement and stabilization of condensed-phase water clusters within other

\footnotetext{
${ }^{a}$ Institut für Ionenphysik und Angewandte Physik, Universität Innsbruck, Technikerstr. 25, A-6020 Innsbruck, Austria. E-mail: paul.scheier@uibk.ac.at

${ }^{b}$ Department of Physics, University of Sargodha, 40100 Sargodha, Pakistan

${ }^{c}$ Department of Physics, Karaj Branch, Islamic Azad University, Karaj, Iran

${ }^{d}$ Department of Nuclear Physics and Biophysics, Comenius University, SK-84248 Bratislava, Slovakia

${ }^{e}$ Department of Chemistry, York University, Toronto, ON M3J 1P3, Canada.

E-mail:dkbohme@yorku.ca
}

predesigned hosts, such as organic materials, ${ }^{10}$ inorganic microporous materials ${ }^{11,12}$ and metal-organic frameworks. ${ }^{13-18}$ Such studies, in general, can provide insight into the structure and behavior of condensed-phase water clusters that otherwise cannot be discretely isolated.

Clathrate hydrates in which organic molecules are trapped within a crystal structure of water, as in methane hydrate or "fire ice", are also known. ${ }^{19-22}$ Methane hydrates are thought to occur in the outer regions of the solar system ${ }^{23}$ where the temperatures are low and they also have been found as outcrops on the cold ocean floor. ${ }^{24-26}$

Discrete water clusters are more readily accessible in the gas phase and can be identified, after ionization, using mass spectrometry. Since $1973,{ }^{27}$ mass spectrometry experiments with different sources of water and different modes of ionization consistently have shown $\left(\mathrm{H}_{2} \mathrm{O}\right)_{21} \mathrm{H}^{+}$to be anomalously intense and so have "magic number" stability. $\left(\mathrm{H}_{2} \mathrm{O}\right)_{28} \mathrm{H}^{+}$and $\left(\mathrm{H}_{2} \mathrm{O}\right)_{30} \mathrm{H}^{+}$show similar, although less dominant, intensity anomalies. ${ }^{28} \mathrm{~A}$ "magic number" water cluster has been observed for $\left(\mathrm{H}_{2} \mathrm{O}\right)_{4}$ adsorbed to positively charged fullerenes. ${ }^{29,30}$ Also the protonated tetramer $\left(\mathrm{H}_{2} \mathrm{O}\right)_{4} \mathrm{H}^{+}$has been mentioned as a particularly stable cluster in the literature. ${ }^{31-33}$ The enhanced stability of $\left(\mathrm{H}_{2} \mathrm{O}\right)_{21} \mathrm{H}^{+}$has been 
attributed to a regular dodecahedral cage structure encaging a $\mathrm{H}_{2} \mathrm{O}$ molecule within the cavity and has found support from theoretical calculations and the known polyhedral clathrate hydrates. ${ }^{34-42}$ However, there appear to have been no previous demonstrations of the confinement and stabilization of water clusters as guests within host molecules in the gas phase. ${ }^{43}$ However, the confinement of protonated water clusters, consisting of $n=20$ and 21 molecules, in TMA was explored by Castleman and coworkers and the results support a dodecahedral arrangement of the water molecules. ${ }^{44}$

Here we report an experimental study of water clusters as guests in interactions with clusters of adamantane as hosts that occur in doped helium droplets at extremely low temperatures $(0.37 \mathrm{~K})$ with mass spectrometric detection. The guest water clusters are first investigated separately in the absence of a host; our studies of the host adamantane clusters already have appeared in the literature. ${ }^{45}$ The main focus here is on the water guest/adamantane host interactions in very cold helium droplets in which cluster formation is enhanced for both the guest and the host molecules. This provides an opportunity to study the accommodation of various sizes of water clusters by various sizes of host adamantane aggregates in the gas phase, including the accommodation of magic number water clusters by magic number adamantane clusters.

\section{Experimental methods}

Helium nanodroplets (HND) were produced by expanding helium (Linde, purity 99.9999\%) at a stagnation pressure of $2.1 \mathrm{MPa}$ through a $5 \mu \mathrm{m}$ nozzle, cooled by a closed-cycle refrigerator to $9.6 \mathrm{~K}$, into vacuum. At these conditions the droplets contain an estimated average number of $4 \times 10^{5}$ helium atoms. ${ }^{46}$ The expanding beam was skimmed by a $0.8 \mathrm{~mm}$ conical skimmer located $8 \mathrm{~mm}$ downstream from the nozzle and traverses a differentially pumped pick-up cell. Adamantane (Sigma Aldrich, $\geq 99 \%$ purity) was introduced via a heated tube from a reservoir attached to the vacuum chamber and kept at a temperature of 313 K. Water (Sigma Aldrich, UHPLC grade) was used after three freeze pump thaw cycles at the inlet system of the instrument. The vapor from the headspace at room temperature was introduced via a heated inlet and the pressure in the pickup region was controlled by a regulated leak valve. Both molecules are heliophilic ${ }^{47,48}$ and enter the droplet where they quickly decelerate to the Landau critical velocity. ${ }^{49}$ Collision of dopants leads to cluster growth and the binding energy is released into the surrounding He matrix and results in the evaporations of $1600 \mathrm{He}$ atoms per $\mathrm{eV} .{ }^{50}$ As the growth process of the neutral dopant clusters is purely statistical, we expect that the cluster size distribution of the dopant clusters before ionization is free of any magic numbers. After the pickup of adamantane and water, the beam of the doped helium droplets was collimated and crossed by an electron beam with a nominal energy between 50 and $100 \mathrm{eV}$. Cations were accelerated into the extraction region of a reflectron time-of-flight mass spectrometer (TofwerkAG, model HTOF) with an effective mass resolution $m / \Delta m \sim 4000$ ( $\Delta m=$ full-width-at-half-maximum).
Further experimental details and possibilities of this setup have been published elsewhere. ${ }^{51-55}$

As in several previous investigations, when we doped HNDs with two dopants, we do not see noticeable differences in the mass spectra when changing the pickup sequence of the two species. This seems to be in contradiction to core-shell nanoparticles grown in large HNDs that have been investigated by transmission electron microscopy after soft-landing. ${ }^{56-59}$ Also, for water clusters surrounded by another small molecular dopant or Ar, Liu et al. report a small co-dopant effect on the fragmentation of the resulting water cluster ions. ${ }^{60}$ In the present study, the number of dopants being picked-up is lower than 100 in contrast to several 1000 in case of the core-shell nanoparticles. Furthermore, the highly exothermic ionization process, i.e., charge transfer from $\mathrm{He}^{+}$, is expected to scramble the dopant cluster.

Mass spectra were evaluated by means of customized software designed to extract the abundance of specific ions after deconvoluting possible overlapping contributions to particular mass peaks by different ions and isotopologues. ${ }^{61}$ The software automatically fits mass peaks, subtracts background signals, and explicitly considers isotopic patterns of all ions that are expected to contribute to a given peak.

\section{Results and discussion}

\section{Water clusters in helium droplets}

We first performed helium droplet experiments with only water being injected (pump freeze methods) before exposure of the droplets to an ionizing electron beam. The resulting mass spectrum recorded under these conditions is shown in Fig. 1. Water clusters appear as protonated clusters $\left(\mathrm{H}_{2} \mathrm{O}\right)_{m} \mathrm{H}^{+}$rather than ionized clusters $\left(\mathrm{H}_{2} \mathrm{O}\right)_{m}{ }^{+}$as $\mathrm{H}_{3} \mathrm{O}^{+}$ions, formed by reactions of $\mathrm{H}_{2} \mathrm{O}^{+}$with $\mathrm{H}_{2} \mathrm{O}$, are a source of protons for water clusters with

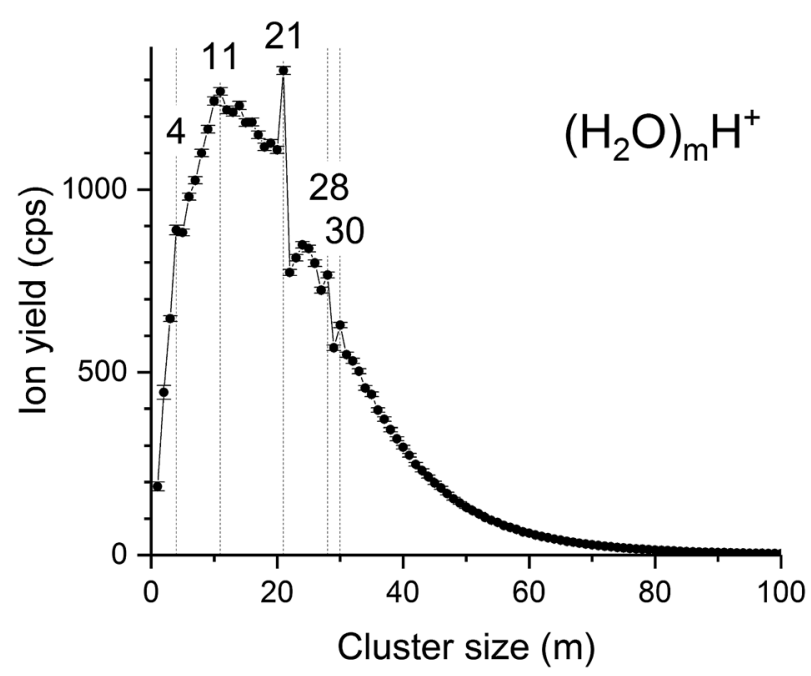

Fig. 1 Experimental results for protonated water-cluster formation in helium droplets. The protonated water cluster series shows a very high relative abundance of the $\left(\mathrm{H}_{2} \mathrm{O}\right)_{21} \mathrm{H}^{+}$cluster and slightly enhanced abundances for $\left(\mathrm{H}_{2} \mathrm{O}\right)_{28} \mathrm{H}^{+}$and $\left(\mathrm{H}_{2} \mathrm{O}\right)_{30} \mathrm{H}^{+}$. Conditions: $T_{\mathrm{He}}=9.5 \mathrm{~K}$, $p_{\mathrm{He}}=2.2 \mathrm{MPa}$, average droplet size $10^{6}$, water pressure $0.23 \mathrm{mPa}$, $E_{\mathrm{el}}=50 \mathrm{eV}, l_{\mathrm{el}}=40 \mu \mathrm{A}$. 
$n=2$ and higher, as illustrated by the following intracluster proton-transfer reaction, eqn (1). ${ }^{13}$

$$
\left(\mathrm{H}_{2} \mathrm{O}\right)_{n} \rightarrow\left(\mathrm{H}_{2} \mathrm{O}\right)_{n}^{+} \rightarrow\left(\mathrm{H}_{2} \mathrm{O}\right)_{m} \mathrm{H}^{+}+(n-m-1) \mathrm{H}_{2} \mathrm{O}+\mathrm{OH}
$$

A clear maximum is seen in the spectrum in Fig. 1 for the protonated water cluster $\left(\mathrm{H}_{2} \mathrm{O}\right)_{21} \mathrm{H}^{+}$. Also interesting to note are minor maxima corresponding to $\left(\mathrm{H}_{2} \mathrm{O}\right)_{4} \mathrm{H}^{+}, \quad\left(\mathrm{H}_{2} \mathrm{O}\right)_{11} \mathrm{H}^{+}$, $\left(\mathrm{H}_{2} \mathrm{O}\right)_{28} \mathrm{H}^{+}$and $\left(\mathrm{H}_{2} \mathrm{O}\right)_{30} \mathrm{H}^{+}$, all of which have been observed previously in other gas-phase experiments, ${ }^{28,31}$ and by us in recent $\mathrm{HND}$ experiments with $\mathrm{D}_{2} \mathrm{O},{ }^{62}$ and again likely due to enhanced stabilities. Clearly then, the observation of magicnumber protonated water clusters generated from the ionization of helium-solvated neutral water clusters is reminiscent of the distribution of ionized water clusters generated from either the VUV photoionization of neutral beams of gas-phase water clusters ${ }^{63}$ or from the discharge of rare-gas supersonic expansions containing dilute water vapor. ${ }^{40}$

\section{Clusters of adamantane in helium droplets}

We have previously reported the results of our study of adamantane clusters in helium droplets. ${ }^{44}$ High-resolution mass spectrometry revealed the presence of "magic number" $\mathrm{m} / \mathrm{z}$ peaks that can be attributed to the packing of adamantine molecules into cluster structures of special stability involving preferred arrangements of these molecules. Magic numbers were observed for $\mathrm{Ad}_{n}^{+}$for $n=13$, 19, 38, 52, 61, 70, 75, 79, 82, 86, 90, 94, 98, 104, 108, 112, 116, 120 and 124. The magic numbers of 13 and 19, which are in the range of the adamantane experiments reported here, could be attributed to the packing of a cation that leads to closure of the first icosahedral shell $(n=13)$ and the formation of a nested icosahedron $(n=19)$. Further packing to form the next icosahedron $(n=55)$ did not seem to occur.

\section{Mixed clusters of adamantane and water in helium droplets}

Fig. 2 displays a mass spectrum of helium nanodroplets doped with both adamantane and water. The prominent mass peaks

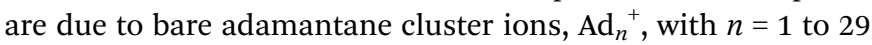
and $n=13(\mathrm{~m} / z=1768)$ and $19(\mathrm{~m} / z=2584)$ being relatively more intense. Water/adamantane clusters of the type $\left(\mathrm{H}_{2} \mathrm{O}\right)_{m} \mathrm{Ad}_{n}{ }^{+}$are clearly visible throughout.

Expanded portions of the spectra in Fig. 2 are shown in Fig. 3 for clusters $\left(\mathrm{H}_{2} \mathrm{O}\right)_{m} \mathrm{Ad}_{n}{ }^{+}$with $n=11$ to 21 to provide a closer look at the water pattern $\left(\mathrm{H}_{2} \mathrm{O}\right)_{m}$ and to search for possible magic water/adamantane clusters, $\left(\mathrm{H}_{2} \mathrm{O}\right)_{21} \mathrm{Ad}_{n}{ }^{+}$with $n=13$ and 19.

Extensive hydration is seen in Fig. 3 for all the adamantane clusters. The distribution in water content is especially striking for the water/adamantane clusters $\left(\mathrm{H}_{2} \mathrm{O}\right)_{m} \mathrm{Ad}_{12}{ }^{+}$and $\left(\mathrm{H}_{2} \mathrm{O}\right)_{m} \mathrm{Ad}_{18}{ }^{+}$ for which generally the water content is significantly enhanced with distributions in water content that peak at $m=10$ and 13, respectively. The magic number clusters $\left(\mathrm{H}_{2} \mathrm{O}\right)_{21} \mathrm{Ad}_{n-2}{ }^{+}$are seen in Fig. 3 for all the adamantane clusters from $n=9$ to 18 and again the water/adamantane clusters $\left(\mathrm{H}_{2} \mathrm{O}\right)_{21} \mathrm{Ad}_{12}{ }^{+}$and $\left(\mathrm{H}_{2} \mathrm{O}\right)_{21} \mathrm{Ad}_{18}{ }^{+}$stand out in intensity.

Clathrate hydrates in which adamantane is trapped within structured water appear to be absent. Based on what we know

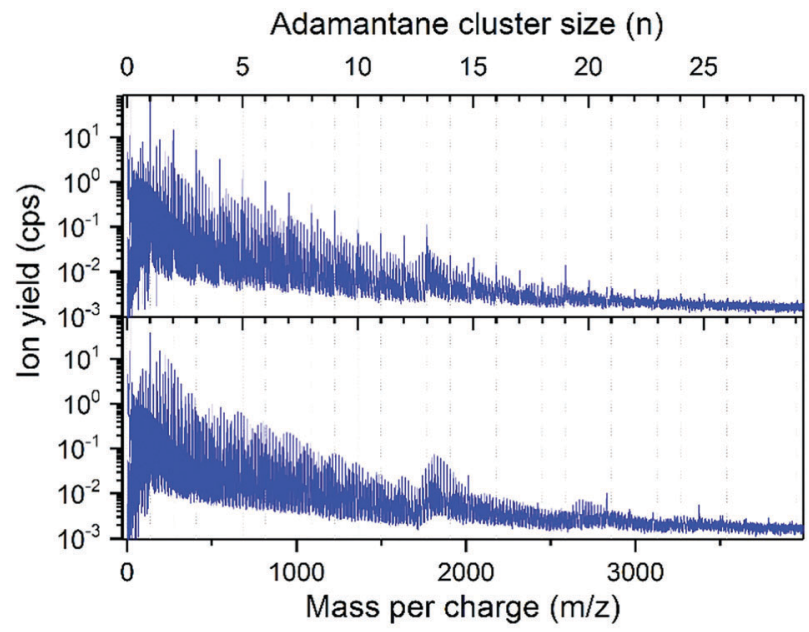

Fig. 2 Two mass spectra of helium nanodroplets doped with adamantane, $\mathrm{C}_{10} \mathrm{H}_{16}$ (molecular weight $\left.=136\right)$ and $\mathrm{H}_{2} \mathrm{O}$ (molecular weight $=18$ ). Conditions: $T_{\mathrm{He}}=9.5 \mathrm{~K}, p_{\mathrm{He}}=2 \mathrm{MPa}$, average droplet size $10^{6}$, adamantane pressure: $0.5 \mathrm{mPa}, E_{\mathrm{el}}=90 \mathrm{eV}, I_{\mathrm{el}}=28 \mu \mathrm{A}$, upper panel: water pressure in the second pickup chamber: $0.1 \mathrm{mPa}$, lower panel: $1.15 \mathrm{mPa}$.

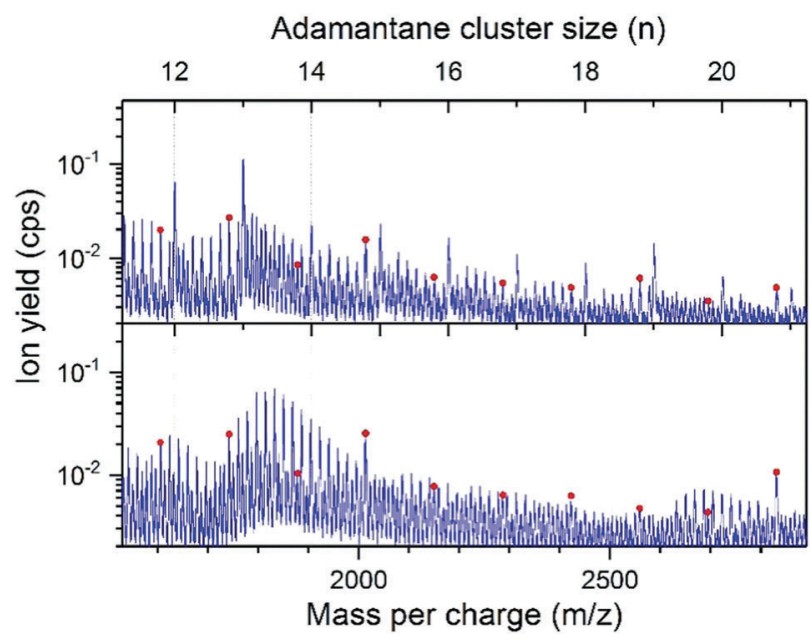

Fig. 3 Sections of the mass spectra shown in Fig. 2 above. Red dots indicate $\left(\mathrm{H}_{2} \mathrm{O}\right)_{21} \mathrm{Ad}_{n-2}{ }^{+}$.

about methane clathrates, we looked for magic large water clusters with small amounts of embedded adamantane. $n=21$ water molecules, and to a lesser extent also $n=28$ and 30, exhibit the only intensity anomalies for any number of adamantane molecules in the clusters. Typical clathrates with small guest molecules such as methane, ethane, carbon dioxide and so on, consist of $85 \mathrm{~mol} \%$ water and 15 mol\% guest(s). ${ }^{58}$ Thus, we conclude that water does not form a clathrate network around such a large number of guest molecules in our experiments.

Fig. 4 focuses on the actual observed cluster size distribution of $\left(\mathrm{H}_{2} \mathrm{O}\right)_{m} \mathrm{Ad}_{n}{ }^{+}$. For $n>5$ we observe the emergence of a magic $m=21$ cluster that becomes more pronounced in relative intensity with increasing adamantane number $n$. Other magic numbers for water clusters attached to adamantane, $\left(\mathrm{H}_{2} \mathrm{O}\right)_{m} \mathrm{Ad}_{n}{ }^{+}$, are as for pristine protonated water, with $m=28$ and $m=30$. Also, for $5<m<21$, the water cluster replaces one adamantane 


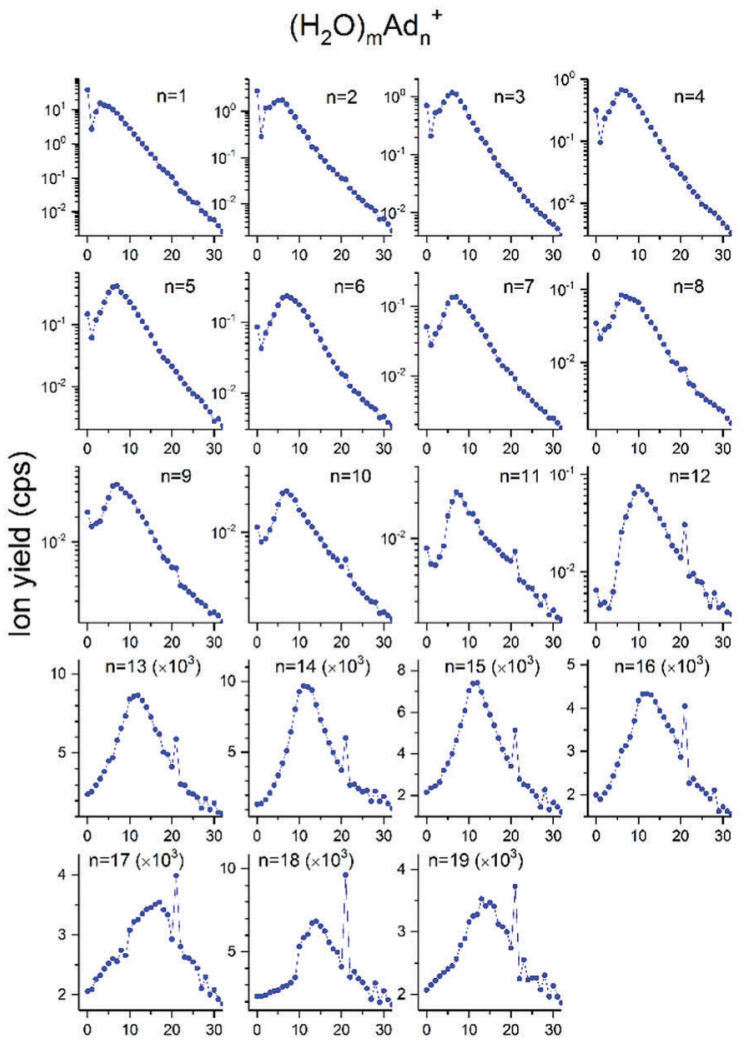

Number of water molecules $(\mathrm{m})$

Fig. 4 Observed cluster size distributions for $\left(\mathrm{H}_{2} \mathrm{O}\right)_{m} \mathrm{Ad}_{n}{ }^{+}$. Please note the logarithmic scale for up to 12 adamantane units. The yields were extracted from the high water pressure spectrum shown in Fig. 2 and 3 with $1.15 \mathrm{mPa} \mathrm{H}_{2} \mathrm{O}$.

(see high yield for all complexes that contain 12,18 or 22 adamantane units and more than 5, 9 or 12 water molecules in Fig. 2-4). Apparently the icosahedral shell closure of pure adamantane at $n=13$ and 19 is preserved with $\left(\mathrm{H}_{2} \mathrm{O}\right)_{21}$ replacing one adamantane unit. The schematic picture in Fig. 5 shows a magic cluster in which 12 adamantane molecules surround, in an icosahedric arrangement, 21 water molecules that form a pentagon dodecahedral structure.

Large adamantane clusters are picked up by large HND, however the volume scales with the cross section to the power 1.5. Thus, after pickup of many adamantane units, there is still more He left to also pick up more water molecules. By reducing the water pressure by a factor of two in the pickup cell, He droplets with a geometric cross section twice as large are able to capture the same amount of water molecules. Thus, for high water pressure, small adamantane complexes exhibit well pronounced maxima for $\left(\mathrm{H}_{2} \mathrm{O}\right)_{21} \mathrm{Ad}_{n}{ }^{+}$, whereas a lower water pressure yields optimum conditions for larger values of $n$ (see Fig. 6).

\section{Clusters in helium droplets doped with heavy water and adamantane}

Heavy water leads to less congested mass spectra as $\left(D_{2} O\right)_{7}$ is four mass units heavier than adamantane, whereas the mass difference between $\left(\mathrm{H}_{2} \mathrm{O}\right)_{15}$ and $\mathrm{Ad}_{2}$ is only 2 mass units which quickly leads to overlapping peak series due to isotopologues

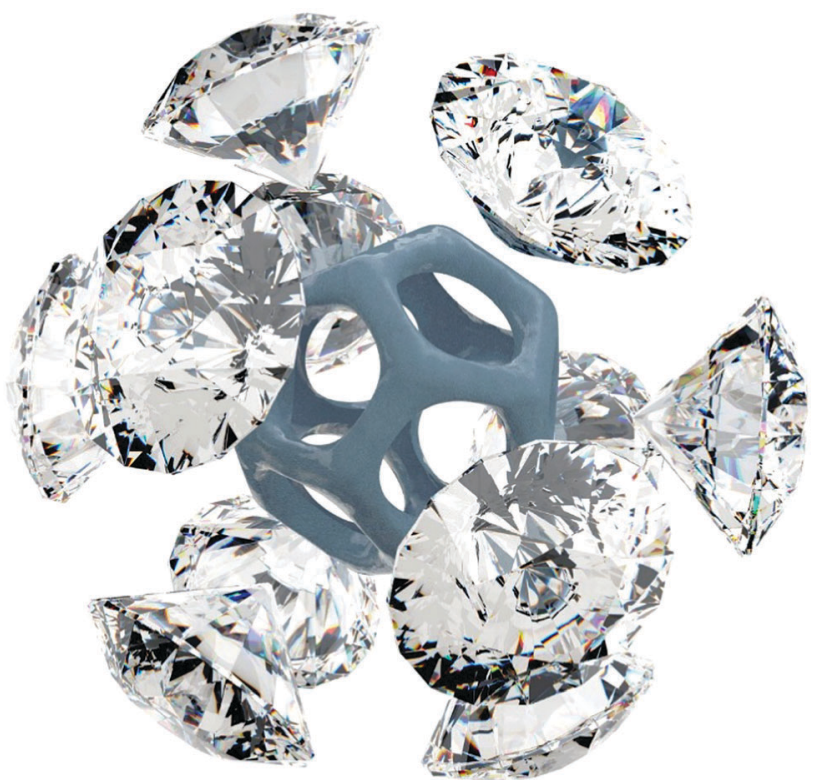

Fig. 5 Schematic picture of a magic cluster in which 12 adamantane "nanodiamonds" surround, in an icosahedric arrangement, 21 water molecules that form a pentagon dodecahedral structure. Each adamantane is placed above the center of a pentagonal face.

containing ${ }^{13} \mathrm{C}$. Fig. 6 and 7 show low and high mass spectra observed in $\mathrm{D}_{2} \mathrm{O}$ /adamantane mixtures over a wide range of $\mathrm{D}_{2} \mathrm{O}$ concentrations.

In Fig. 6, clear magic numbers can be seen at $n=21,28$ and 30 for the ion series of $\left(\mathrm{D}_{2} \mathrm{O}\right)_{m} \mathrm{D}^{+},\left(\mathrm{D}_{2} \mathrm{O}\right)_{m} \mathrm{Ad}^{+}$and $\left(\mathrm{D}_{2} \mathrm{O}\right)_{m} \mathrm{Ad}_{12}{ }^{+}$. For pure water also $m=4$ and 11 are slightly enhanced compared to their neighbors.

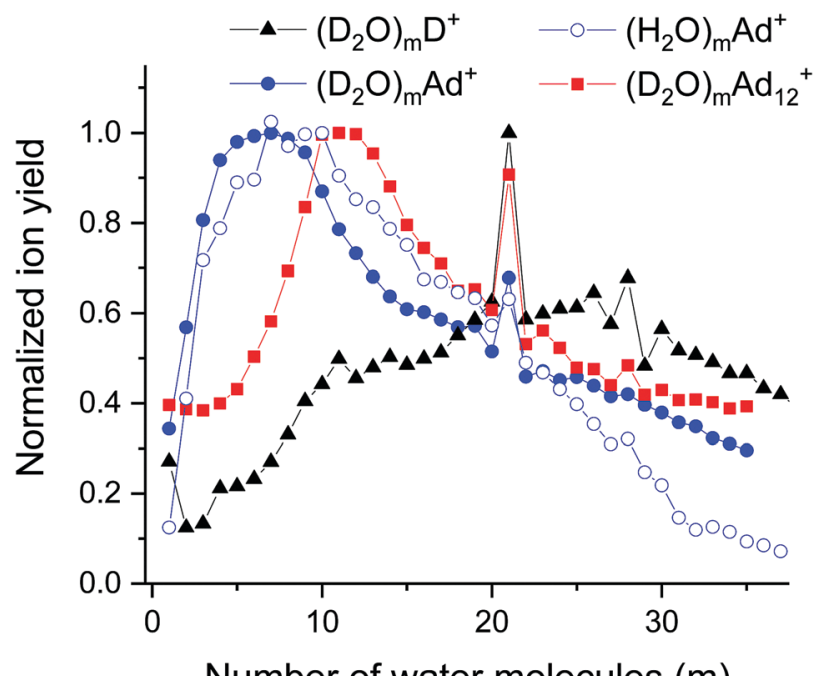

Fig. 6 Cluster size distributions measured for pure (heavy) water clusters $\left(\mathrm{D}_{2} \mathrm{O}\right)_{m} \mathrm{D}^{+}$(solid triangles, $p\left(\mathrm{D}_{2} \mathrm{O}\right)=4 \mathrm{mPa}$ ), water clusters with one adamantane molecule $\left(\mathrm{D}_{2} \mathrm{O}\right)_{m} \mathrm{Ad}^{+}$(solid circles, $p\left(\mathrm{D}_{2} \mathrm{O}\right)=3.98 \mathrm{mPa}$ ), and water clusters with 12 adamantane molecules $\left(\mathrm{D}_{2} \mathrm{O}\right)_{m} \mathrm{Ad}_{12}{ }^{+}$(solid squares, $\left.p\left(\mathrm{D}_{2} \mathrm{O}\right)=2.6 \mathrm{mPa}\right) . T_{\mathrm{He}}=9.7 \mathrm{~K}, p_{\mathrm{He}}=2.4 \mathrm{MPa}$, electron energy $82 \mathrm{eV}$, electron current $206 \mu \mathrm{A}$. For comparison also $\left(\mathrm{H}_{2} \mathrm{O}\right)_{\mathrm{mAd}^{+}}$(open circles) is shown for high water pressure $p\left(\mathrm{H}_{2} \mathrm{O}\right)=4 \mathrm{mPa}$. 


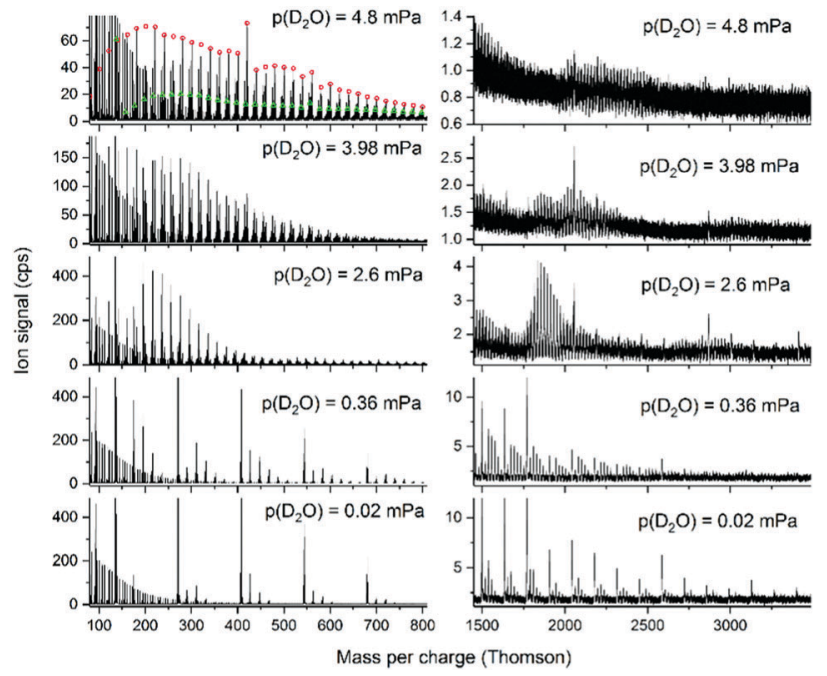

Fig. 7 Sections of mass spectra of ions formed upon electron ionization of HND doped with adamantane and $\mathrm{D}_{2} \mathrm{O}$ at the different water pressures indicated. The adamantane pressure was $0.2 \mathrm{mPa}, T_{\mathrm{He}}=9.7 \mathrm{~K}, p_{\mathrm{He}}=$ $2.4 \mathrm{MPa}, E_{\mathrm{el}}=82 \mathrm{eV}, l_{\mathrm{el}}=206 \mu \mathrm{A}$. The open circles in the upper left mass spectrum designate the $\left(\mathrm{D}_{2} \mathrm{O}\right)_{m} \mathrm{D}^{+}$ions and the open triangles the $\left(\mathrm{D}_{2} \mathrm{O}\right)_{m} \mathrm{Ad}^{+}$ions.

\section{Conclusions}

Clearly, helium nanodroplets provide a low-temperature environment very favorable for the formation of water, adamantane and mixed water/adamantane clusters that can readily be revealed with exposure to ionization and mass-spectrometric detection.

Our pure water-dopant experiments demonstrate that water clusters readily form at the extremely low temperatures of HND. The distribution in the size of the water clusters that is seen mass spectrometrically as $\left(\mathrm{H}_{2} \mathrm{O}\right)_{m} \mathrm{H}^{+}$peaks at $n=11$ and extends beyond $m=100$. Local maxima are exhibited at $m=4,11,21,28$ and 30 with $\left(\mathrm{H}_{2} \mathrm{O}\right)_{21} \mathrm{H}^{+}$being the most anomalous and showing the greatest stability compared to clusters immediately adjacent in water content, as has been observed previously by others with higher temperature gas-phase experiments.

Extensive hydration occurs with all the adamantane clusters and the magic number clusters $\left(\mathrm{H}_{2} \mathrm{O}\right)_{21} \mathrm{Ad}_{n}{ }^{+}$are seen for all the adamantane clusters from $n=9$ to 18 . Other magic numbers for water clusters attached to adamantane, $\left(\mathrm{H}_{2} \mathrm{O}\right)_{m} \mathrm{Ad}_{n}{ }^{+}$, are as for pristine protonated water, with $m=28$ and $m=30$.

For $5<m<21$ the water cluster replaces one adamantane in $\left(\mathrm{H}_{2} \mathrm{O}\right)_{m} \mathrm{Ad}_{n}{ }^{+}$, (high yields are observed for all complexes that contain 12, 18 or 22 adamantane units and more than 5, 9 or 12 water molecules). The icosahedral shell closure of pure adamantine at $n=13$ and 19 appears to be preserved with $\left(\mathrm{H}_{2} \mathrm{O}\right)_{21}$ replacing one adamantane. The water/adamantine clusters $\left(\mathrm{H}_{2} \mathrm{O}\right)_{21} \mathrm{Ad}_{12}{ }^{+}$and $\left(\mathrm{H}_{2} \mathrm{O}\right)_{21} \mathrm{Ad}_{18}{ }^{+}$stand out in intensity and demonstrate the interplay of magic number water clusters with magic number adamantane clusters. This may well be the first observation of the interplay between two magic number clusters in gas-phase cluster chemistry generally. There was no clear evidence for the formation of clathrate hydrates in which adamantine is trapped within structured water.
The observed mass spectra of course do not provide information on the structures of the mixed water/adamantane clusters $\left(\mathrm{H}_{2} \mathrm{O}\right)_{m} \mathrm{Ad}_{n}{ }^{+}$, nor do they provide insight into the dynamics of their formation. These may be accessible with high-level theoretical computations, although these clusters contain many atoms and are generally relatively large in size.

\section{Conflicts of interest}

There are no conflicts to declare.

\section{Acknowledgements}

This work was supported by the FWF projects P26635, W1259, and M1908. L. K. acknowledges gratefully a grant by the KKKÖ. B. R. was supported by an Ernst Mach Follow-up grant and D. K. B. gratefully acknowledges support by York University.

\section{References}

1 G. A. Jeffrey, in Inclusion Compounds, ed. J. L. Atwood, J. E. D. Davies and D. D. MacNicol, Academic Press, New York, 1984, vol. 1, pp. 135-190.

2 E. D. Sloan, Fundamental principles and applications of natural gas hydrates, Nature, 2003, 426, 353-359, DOI: 10.1038/nature02135.

3 M. Chaplin, Do we underestimate the importance of water in cell biology?, Nat. Rev. Mol. Cell Biol., 2006, 7, 861-866, DOI: $10.1038 / \mathrm{nrm} 2021$.

4 S. Wallace, L. Huang, L. Massa, U. Mukhopadhyay, I. Bernal and J. Karle, The structures of cyclic dihydroniumcations, Proc. Natl. Acad. Sci. U. S. A., 2007, 104, 16798-16803, DOI: 10.1073/pnas.0708249104.

5 W. L. Mao, H.-K. Mao, A. F. Goncharov, V. V. Struzhkin, Q. Guo, J. Hu, J. Shu, R. J. Hemley, M. Somayazulu and Y. Zhao, Hydrogen Clusters in Clathrate Hydrate, Science, 2002, 297, 2247-2249, DOI: 10.1126/science.1075394.

6 Y. H. Hu and E. Ruckenstein, Clathrate Hydrogen Hydrate-A Promising Material for Hydrogen Storage, Angew. Chem., Int. Ed., 2006, 45, 2011-2013, DOI: 10.1002/anie.200504149.

7 T. A. Strobel, Y. Kim, G. S. Andrews, J. R. Ferrell III, C. A. Koh, A. M. Herring and E. D. Sloan, Chemical-Clathrate Hybrid Hydrogen Storage: Storage in Both Guest and Host, J. Am. Chem. Soc., 2008, 130, 14975-14977, DOI: 10.1021/ja805492n.

8 S. Takeya and J. A. Ripmeester, Dissociation Behavior of Clathrate Hydrates to Ice and Dependence on Guest Molecules, Angew. Chem., Int. Ed., 2008, 47, 1276-1279, DOI: 10.1002/anie.200703718.

9 M.-L. Cao, J.-J. Wu, H.-J. Mo and B.-H. Ye, Template Trapping and Crystal Structure of the Magic Number $\left(\mathrm{H}_{2} \mathrm{O}\right)_{21}$ Cluster in the Tetrahedral Hole of a Nanoscale Global Ion Packed in a Face-Centered Cubic Pattern, J. Am. Chem. Soc., 2009, 131, 3458-3459, DOI: 10.1021/ja810107a.

10 C.-K. Lam, F. Xue, J.-P. Zhang, X.-M. Chen and T. C. W. Mak, Hydrogen-Bonded Anionic Rosette Networks Assembled 
with Guanidinium and $\mathrm{C}_{3}$-Symmetric Oxoanion Building Blocks, J. Am. Chem. Soc., 2005, 127, 11536-11537, DOI: 10.1021/ja050221a.

11 Y. Lee, T. Vogt, J. A. Hriljac, J. B. Parise, J. C. Hanson and S. J. Kim, Non-framework cation migration and irreversible pressure-induced hydration in a zeolite, Nature, 2002, 420, 485-489, DOI: 10.1038/nature01265.

12 A. Müller, E. Krickemeyer, H. Bögge, M. Schmidtmann, B. Botar and M. O. Talismanova, Drawing Small Cations into Highly Charged Porous Nanocontainers Reveals "Water" Assembly and Related Interaction Problems, Angew. Chem., Int. Ed., 2003, 42, 2085-2090, DOI: 10.1002/anie.200351126.

13 Y.-P. Ren, L.-S. Long, B.-W. Mao, Y.-Z. Yuan, R.-B. Huang and L.-S. Zheng, Nanoporous Lanthanide-Copper(II) Coordination Polymers: Syntheses and Crystal Structures of $\left[\left\{\mathrm{M}_{2}\left(\mathrm{Cu}_{3}-\right.\right.\right.$ (iminodiacetate) $\left.\left.)_{6}\right) \cdot 8 \mathrm{H}_{2} \mathrm{O}\right]_{n}(\mathrm{M}=\mathrm{La}, \mathrm{Nd}, \mathrm{Eu})$, Angew. Chem., Int. Ed., 2003, 42, 532-535, DOI: 10.1002/anie.200390153.

14 M. Yoshizawa, T. Kusukawa, M. Kawano, T. Ohhara, I. Tanaka, K. Kurihara, N. Niimura and M. Fujita, Endohedral Clusterization of Ten Water Molecules into a "Molecular Ice" within the Hydrophobic Pocket of a Self-Assembled Cage, J. Am. Chem. Soc., 2005, 127, 2798-2799, DOI: 10.1021/ja043953w.

15 Y.-C. Liao, Y.-C. Jiang and S.-L. Wang, Discrete Water Hexamers and Template-Assisted Molecular Recognition in an Elastic Zincophosphate Lattice, J. Am. Chem. Soc., 2005, 127, 12794-12795, DOI: 10.1021/ja054357k.

16 P. S. Lakshminarayanan, E. Suresh and P. Ghosh, Formation of an Infinite 2D-Layered Water of $\left(\mathrm{H}_{2} \mathrm{O}\right)_{45}$ Cluster in a Cryptand-Water Supramolecular Complex: A Template Effect, J. Am. Chem. Soc., 2005, 127, 13132-13133, DOI: 10.1021/ ja054068w.

17 H.-B. Cui, B. Zhou, L.-S. Long, Y. Okano, H. Kobayashi and A. Kobayashi, A Porous Coordination-Polymer Crystal Containing One-Dimensional Water Chains Exhibits Guest-Induced Lattice Distortion and a Dielectric Anomaly, Angew. Chem., Int. Ed., 2008, 47, 3376-3380, DOI: 10.1002/anie.200705846.

18 F. Dai, H. He and D. Sun, A Metal-Organic Nanotube Exhibiting Reversible Adsorption of $\left(\mathrm{H}_{2} \mathrm{O}\right)_{12}$ Cluster, J. Am. Chem. Soc., 2008, 130, 14064-14065, DOI: 10.1021/ja805920t.

19 M. R. Walsh, C. A. Koh, E. D. Sloan, A. K. Sum and D. T. Wu, Microsecond Simulations of Spontaneous Methane Hydrate Nucleation and Growth, Science, 2009, 326, 1095-1098, DOI: 10.1126/science.1174010.

20 K. A. Udachin and J. A. Ripmeester, A complex clathrate hydrate structure showing bimodal guest hydration, Nature, 1999, 397, 420-423, DOI: 10.1038/17097.

21 H. Tanaka, T. Yagasaki and M. Matsumoto, On the Thermodynamic Stability of Clathrate Hydrates VI: Complete Phase Diagram, J. Phys. Chem. B, 2018, 122, 297-308, DOI: 10.1021/ acs.jpcb.7b10581.

22 B. C. Knott, V. Molinero, M. F. Doherty and B. Peters, Homogeneous Nucleation of Methane Hydrates: Unrealistic under Realistic Conditions, J. Am. Chem. Soc., 2012, 134, 19544-19547, DOI: 10.1021/ja309117d.

23 O. Mousis, E. Chassefiere, N. G. Holm, A. Bouquet, J. H. Waite, W. D. Geppert, S. Picaud, Y. Aikawa, M. Ali-Dib, J. L. Charlouand and P. Rousselot, Methane Clathrates in the Solar System, Astrobiology, 2015, 15, 308-326, DOI: 10.1089/ast.2014.1189.

24 A. Falenty, T. C. Hansen and W. F. Kuhs, Formation and properties of ice XVI obtained by emptying a type sII clathrate hydrate, Nature, 2014, 516, 231-233, DOI: 10.1038/nature14014.

25 B. Buffett and D. Archer, Global inventory of methane clathrate: sensitivity to changes in the deep ocean, Earth Planet. Sci. Lett., 2004, 227, 185-199, DOI: 10.1016/j.epsl.2004.09.005.

26 D. Archer, B. Buffett and V. Brovkin, Ocean methane hydrates as a slow tipping point in the global carbon cycle, Proc. Natl. Acad. Sci. U. S. A., 2009, 106, 20596-20601, DOI: 10.1073/pnas.0800885105.

27 S. Lin, Detection of Large Water Clusters by a Low rf Quadrupole Mass Filter, Rev. Sci. Instrum., 1973, 44, 516-517, DOI: $10.1063 / 1.1686172$.

28 For $n=28$ and 30 see, for example, U. Nagashima, H. Shinohara, N. Nishi and H. Tanaka, Enhanced stability of ion-clathrate structures for magic number water clusters, J. Chem. Phys., 1986, 84, 209-214, DOI: 10.1063/1.450172.

29 S. Denifl, F. Zappa, I. Mähr, F. Ferreira da Silva, A. Aleem, A. Mauracher, M. Probst, J. Urban, P. Mach and A. Bacher, et al., Ion-Molecule Reactions in Helium Nanodroplets Doped with $\mathrm{C}_{60}$ and Water Clusters, Angew. Chem., Int. Ed., 2009, 48, 8940-8943, DOI: 10.1002/anie.200904381.

30 J. Hernandez-Rojas, F. Calvo, F. Rabilloud, J. Breton and J. M. G. Llorente, Modeling Water Clusters on Cationic Carbonaceous Seeds, J. Phys. Chem. A, 2010, 114, 7267-7274, DOI: 10.1021/jp101584n.

31 S. A. McLuckey, G. L. Glish, K. G. Asano and J. E. Bartmess, Protonated water and protonated methanol cluster decompositions in a quadrupole ion trap, Int. J. Mass Spectrom. Ion Processes, 1991, 109, 171-186, DOI: 10.1016/0168-1176(91)85103-S.

32 Y. K. Lau, S. Ikuta and P. Kebarle, Thermodynamics and kinetics of the gas-phase reactions $\mathrm{H}_{3} \mathrm{O}^{+}\left(\mathrm{H}_{2} \mathrm{O}\right)_{n-1}+$ water $=$ $\mathrm{H}_{3} \mathrm{O}^{+}\left(\mathrm{H}_{2} \mathrm{O}\right)_{n}$, J. Am. Chem. Soc., 1982, 104, 1462-1469, DOI: 10.1021/ja00370a002.

33 M. Meot-Ner and C. V. Speller, Filling of solvent shells about ions. 1. Thermochemical criteria and the effects of isomeric clusters, J. Phys. Chem., 1986, 90, 6616-6624, DOI: 10.1021/j100283a006.

34 J. L. Kassner and D. E. Hagen, Comment on "Clustering of water on hydrated protons in a supersonic free jet expansion", J. Chem. Phys., 1976, 64, 1860-1861, DOI: 10.1063/1.432330.

$35 \mathrm{X}$. Yang and A. W. Castleman Jr., Large protonated water clusters $\mathrm{H}^{+}\left(\mathrm{H}_{2} \mathrm{O}\right)_{n}(1 \leq n<60)$ : the production and reactivity of clathrate-like structures under thermal conditions, J. Am. Chem. Soc., 1989, 111, 6845-6846, DOI: 10.1021/ja00199a056.

36 S. W. Lee, P. Freivogel, T. Schindler and J. L. Beauchamp, Freeze-Dried Biomolecules: FT-ICR Studies of the Specific Solvation of Functional Groups and Clathrate Formation Observed by the Slow Evaporation of Water from Hydrated Peptides and Model Compounds in the Gas Phase, J. Am. Chem. Soc., 1998, 120, 11758-11765, DOI: 10.1021/ja982075x.

37 S. König and H. M. Fales, Formation and decomposition of water clusters as observed in a triple quadrupole mass spectrometer, J. Am. Soc. Mass Spectrom, 1998, 9, 814-822, DOI: 10.1016/S1044-0305(98)00044-0. 
38 M. Miyazaki, A. Fujii, T. Ebata and N. Mikami, Infrared Spectroscopic Evidence for Protonated Water Clusters Forming Nanoscale Cages, Science, 2004, 304, 1134-1137, DOI: 10.1126/science.1096037.

39 J.-W. Shin, N. I. Hammer, E. G. Diken, M. A. Johnson, R. S. Walter, T. D. Jaeger, M. A. Duncan, R. A. Christie and K. D. Jordan, Infrared Signature of Structures Associated with the $\mathrm{H}^{+}\left(\mathrm{H}_{2} \mathrm{O}\right)_{n}$ ( $n=6$ to 27) Clusters, Science, 2004, 304, 1137-1140, DOI: 10.1126/science.1096466.

40 C.-C. Wu, C.-K. Lin, L.-C. Chang, J.-C. Jiang, J.-L. Kuo and M. L. Klein, Protonated clathrate cages enclosing neutral water molecules: $\mathrm{H}^{+}\left(\mathrm{H}_{2} \mathrm{O}\right)_{21}$ and $\mathrm{H}^{+}\left(\mathrm{H}_{2} \mathrm{O}\right)_{28}$, J. Chem. Phys., 2005, 122, 074315, DOI: 10.1063/1.1843816.

41 M. F. Bush, R. J. Saykally and E. R. Williams, Infrared Action Spectra of $\mathrm{Ca}^{2+}\left(\mathrm{H}_{2} \mathrm{O}\right)_{11-69}$ Exhibit Spectral Signatures for Condensed-Phase Structures with Increasing Cluster Size, J. Am. Chem. Soc., 2008, 130, 15482-15489, DOI: 10.1021/ja804621r.

42 T. C. W. Mak and R. K. McMullan, Polyhedral Clathrate Hydrates. X. Structure of the Double Hydrate of Tetrahydrofuran and Hydrogen Sulfide, J. Chem. Phys., 1965, 42, 2732-2737, DOI: 10.1063/1.1703229.

43 T. S. Zwier, The Structure of Protonated Water Clusters, Science, 2004, 304, 1119-1120, DOI: 10.1126/science.1098129.

44 S. Wei, Z. Shi and A. W. Castleman, Mixed cluster ions as a structure probe: experimental evidence for clathrate structure of $\left(\mathrm{H}_{2} \mathrm{O}\right)_{20} \mathrm{H}^{+}$and $\left(\mathrm{H}_{2} \mathrm{O}\right)_{21} \mathrm{H}^{+}$, J. Chem. Phys., 1991, 94, 3268-3270, DOI: $10.1063 / 1.459796$.

45 M. Goulart, M. Kuhn, L. Kranabetter, A. Kaiser, J. Postler, M. Rastogi, A. Aleem, B. Rasul, D. K. Bohme and P. Scheier, Magic Numbers for Packing Adamantane in Helium Droplets: Cluster Cations, Dications, and Trications, J. Phys. Chem. C, 2017, 121, 10767-10772, DOI: 10.1021/acs.jpcc.6b11330.

46 L. F. Gomez, E. Loginov, R. Sliter and A. F. Vilesov, Sizes of large He droplets, J. Chem. Phys., 2011, 135, 154201, DOI: 10.1063/ 1.3650235 .

47 F. Ancilotto, P. B. Lerner and M. W. Cole, Physics of solvation, J. Low Temp. Phys., 1995, 101, 1123-1146, DOI: 10.1007/ Bf00754527.

48 J. Poms, A. W. Hauser and W. E. Ernst, Helium nanodroplets doped with xenon and rubidium atoms: a case study of van der Waals interactions between heliophilic and heliophobic dopants, Phys. Chem. Chem. Phys., 2012, 14, 15158-15165, DOI: $10.1039 / \mathrm{c} 2 \mathrm{cp} 42333 \mathrm{~b}$.

49 N. B. Brauer, S. Smolarek, E. Loginov, D. Mateo, A. Hernando, M. Pi, M. Barranco, W. J. Buma and M. Drabbels, Critical Landau Velocity in Helium Nanodroplets, Phys. Rev. Lett., 2013, 111, 153002, DOI: 10.1103/PhysRevLett.111.153002.

50 A. Mauracher, O. Echt, A. M. Ellis, S. Yang, D. K. Bohme, J. Postler, A. Kaiser, S. Denifl and P. Scheier, Cold Physics and Chemistry: Collisions, Ionization and Reactions inside Helium Nanodroplets Close to Zero K, Phys. Rep., 2018, DOI: 10.1016/j.physrep.2018.05.001.

51 H. Schöbel, P. Bartl, C. Leidlmair, S. Denifl, O. Echt, T. D. Märk and P. Scheier, High-resolution mass spectrometric study of pure helium droplets, and droplets doped with krypton, Eur. Phys. J. D, 2011, 63, 209-214, DOI: 10.1140/epjd/e2011-10619-1.

52 M. Renzler, L. Kranabetter, M. Goulart, P. Scheier and O. Echt, Positively and Negatively Charged Cesium and $\left(\mathrm{C}_{60}\right)_{m} \mathrm{Cs}_{n}$ Cluster Ions, J. Phys. Chem. C, 2017, 121, 10817-10823, DOI: 10.1021/ acs.jpcc.6b11928.

53 N. Weinberger, J. Postler, P. Scheier and O. Echt, Nitrogen Cluster Anions, J. Phys. Chem. C, 2017, 121, 10632-10637, DOI: $10.1021 /$ acs.jpcc.6b09211.

54 M. Renzler, M. Kuhn, A. Mauracher, A. Lindinger, P. Scheier and A. M. Ellis, Anionic Hydrogen Cluster Ions as a New Form of Condensed Hydrogen, Phys. Rev. Lett., 2016, 117, 273001, DOI: 10.1103/PhysRevLett.117.273001.

55 M. Kuhn, M. Renzler, J. Postler, S. Ralser, S. Spieler, M. Simpson, H. Linnartz, A. G. G. M. Tielens, J. Cami and A. Mauracher, et al., Atomically resolved phase transition of fullerene cations solvated in helium droplets, Nat. Commun., 2016, 7, 13550, DOI: 10.1038/ncomms13550.

56 V. Mozhayskiy, M. N. Slipchenko, V. K. Adamchuk and A. F. Vilesov, Use of helium nanodroplets for assembly, transport, and surface deposition of large molecular and atomic clusters, J. Chem. Phys., 2007, 127, 094701, DOI: 10.1063/1.2759927.

57 A. Boatwright, C. Feng, D. Spence, E. Latimer, C. Binns, A. M. Ellis and S. Yang, Helium droplets: a new route to nanoparticles, Faraday Discuss., 2013, 162, 113-124, DOI: 10.1039/c2fd20136d.

58 P. Thaler, A. Volk, F. Lackner, J. Steurer, D. Knez, W. Grogger, F. Hofer and W. E. Ernst, Formation of bimetallic core-shell nanowires along vortices in superfluid He nanodroplets, Phys. Rev. B: Condens. Matter Mater. Phys., 2014, 90, 155442, DOI: 10.1103/PhysRevB.90.155442.

59 M. Lasserus, M. Schnedlitz, D. Knez, R. Messner, A. Schiffmann, F. Lackner, A. W. Hauser, F. Hofer and W. E. Ernst, Thermally induced alloying processes in a bimetallic system at the nanoscale: AgAu sub-5 nm core-shell particles studied at atomic resolution, Nanoscale, 2018, 10, 2017-2024, DOI: 10.1039/ c7nr07286d.

60 J. Liu, B. Shepperson, A. M. Ellis and S. Yang, Core-shell effects in the ionization of doped helium nanodroplets, Phys. Chem. Chem. Phys., 2011, 13, 13920-13925, DOI: 10.1039/ c1cp20653b.

61 S. Ralser, J. Postler, M. Harnisch, A. M. Ellis and P. Scheier, Extracting cluster distributions from mass spectra: IsotopeFit, Int. J. Mass Spectrom., 2015, 379, 194-199, DOI: 10.1016/ j.ijms.2015.01.004.

62 S. Denifl, F. Zappa, I. Mähr, A. Mauracher, M. Probst, J. Urban, P. Mach, A. Bacher, D. K. Bohme, O. Echt, T. D. Märk and P. Scheier, Ionization of doped helium nanodroplets: complexes of $\mathrm{C}_{60}$ with water clusters, J. Chem. Phys., 2010, 132, 234307, DOI: 10.1063/1.3436721.

63 L. Belau, K. R. Wilson, S. R. Leone and M. Ahmed, Vacuum Ultraviolet (VUV) Photoionization of Small Water Clusters, J. Phys. Chem. A, 2007, 111, 10075-10083, DOI: 10.1021/jp075263v. 